\title{
Time-Resolved Photodissociation Study of Singly Protonated Peptides with a Histidine Residue Generated by Matrix-Assisted Laser Desorption Ionization: Dissociation Rate Constant and Internal Temperature
}

\author{
So Hee Yoon, ${ }^{\text {a Jeong Hee Moon, }}{ }^{\mathrm{b}}$ and Myung Soo Kim ${ }^{\mathrm{a}}$ \\ ${ }^{a}$ Department of Chemistry, Seoul National University, Seoul, Korea \\ ${ }^{b}$ Medical Proteomics Research Center, KRIBB, Daejeon, Korea
}

Product ion yields in post-source decay and time-resolved photodissociation at 193 and $266 \mathrm{~nm}$ were measured for some peptide ions with a histidine residue $\left(\left[\mathrm{HF}_{6}+\mathrm{H}\right]^{+},\left[\mathrm{F}_{6} \mathrm{H}+\mathrm{H}\right]^{+}\right.$, and $\left[\mathrm{F}_{3} \mathrm{HF}_{3}+\mathrm{H}\right]^{+}$) formed by matrix-assisted laser desorption ionization (MALDI). Compared with similar data for peptide ions without any basic residue reported previously, significant reduction in dissociation efficiency was observed. Internal temperatures $(T)$ of the peptide ions and their dissociation kinetic parameters-the critical energy $\left(E_{0}\right)$ and entropy $\left(\Delta S^{\ddagger}\right)$-were determined by the method reported previously. Slight decreases in $E_{0}, \Delta S^{\ddagger}$, and $T$ were responsible for the histidine effect-reduction in dissociation rate constant. Regardless of the presence of the residue, $\Delta S^{\ddagger}$ was far more negative than previous quantum chemical results. Based on this, we propose the existence of transition structures in which the nitrogen atoms in the histidine residue or at the $\mathrm{N}$-terminus coordinate to the reaction centers. Reduction in $T$ in the presence of a histidine residue could not be explained based on popular models for ion formation in MALDI, such as the gas-phase proton transfer model. (J Am Soc Mass Spectrom 2009, 20, 1522-1529) (C) 2009 American Society for Mass Spectrometry

$\mathrm{T}$ Tandem mass spectral information-list of product ions formed from a precursor ion and their relative intensities-is tremendously useful for peptide and protein sequencing [1]. Pioneering studies on the product ion species formed from protonated peptides generated by fast atom bombardment and the mechanistic explanations for their formation were made by Martin and Biemann [2]. Extensive investigations followed [3-5], which were made mostly for protonated peptides generated by matrix-assisted laser desorption ionization (MALDI) [6] and electrospray ionization (ESI) [7]. For small model peptide ions, investigations beyond simple mechanistic interpretation have been reported, such as the quantum chemical search for reaction paths [8-10]. However, there has not been much study on kinetics of peptide ion dissociation [11].

Tandem mass spectral patterns for protonated peptides are affected by factors, such as the charge state, the number of arginine residue, and the energy regime $[2,3$, $12,13]$. For singly protonated peptides-these will be called peptide ions from now on-without an arginine residue, $\mathrm{b}$ and $\mathrm{y}$ types (see reference [2] for product ion

Address reprint requests to Professor M. S. Kim, Department of Chemistry, College of Natural Sciences, Seoul National University, Seoul 151-742, Korea. E-mail: myungsoo@snu.ac.kr symbols) are the major product ions regardless of the energy regime. Oxazolone pathways [4, 8-10] have been proposed to explain their formation, which consist of the migration of the additional proton to an amide nitrogen, rate-determining cleavage of the protonated amide bond via a five-membered ring transition structure, formation of a proton-bound dimer of an oxazolone derivative and a smaller peptide, and its breakup. For peptide ions with an arginine residue, b/y channels (rearrangement) are dominant in the lowenergy regime [3], such as in low-energy collisionally activated dissociation (CAD) and post-source decay (PSD). In the high-energy regime, such as in highenergy CAD [2] and ultraviolet photodissociation (UVPD) [12-14], however, a new set of homolytic $\mathrm{C}_{\alpha}-\mathrm{CO}$ cleavage channels become dominant, even though the rearrangement channels still operate.

Statistical theory of mass spectra (Rice-RamspergerKassel-Marcus theory, RRKM) [15] is known to provide an excellent description for the dissociation of small polyatomic ions. There have been some debates on whether RRKM would be valid for dissociation of large biomolecules [16]. Recently, we observed that the UV-PD tandem mass spectral patterns obtained with the side-chain $(266 \mathrm{~nm})$ and backbone $(193 \mathrm{~nm})$ excitations were similar $[13,17]$. This suggests that dissociations occur in a common electronic state, probably the 
ground state, regardless of the excited state accessed by activation. Steady increase of the dissociation rate with the internal energy $(E)$ was also observed [18], as dictated by RRKM.

RRKM rate-energy relation, $k(E)$, is essentially determined by two parameters [15], viz. the critical energy $\left(E_{0}\right)$ and entropy $\left(\Delta S^{\ddagger}\right)$. A systematic method to calculate $k(E)$ for peptide ions is available $[19,20]$. Regardless, rigorous RRKM analysis of tandem mass spectral data for peptide ions is a formidable problem because many competing and consecutive reactions participate [21], requiring more than one set of $\left(E_{0}, \Delta S^{\ddagger}\right)$ for the kinetic analysis. Assuming that the kinetic properties of $\mathrm{b} / \mathrm{y}$ channels occurring at different amide bonds are similar, the total rate constant, $k_{\text {tot }}(E)$, for peptide ions without an arginine residue may be estimated by calculating $k(E)$ for a typical (average) channel and multiplying the result by the number of amide bonds- the approach taken in our previous study [18]. Kinetic analysis will be more difficult in the presence of an arginine residue, because at least two sets of $\left(E_{0}, \Delta S^{\ddagger}\right)$ would be needed, one for the rearrangements and the other for the homolytic cleavages. Another factor needed for RRKM analysis is the precursor ion internal energy or its distribution $(P(E))$. Determination of $P(E)$ for peptide ions generated by MALDI is an outstanding problem itself [22]. In a previous work [18], we simplified this difficulty by assuming that peptide ions were in internal thermal equilibrium at an effective temperature $T$ [22]. Then, experimental product ion yield data in PSD and UV-PD were compared with the theoretical results estimated by RRKM calculations.

Presence of a basic residue in a peptide ion may affect its dissociation, as observed for ions with an arginine residue. Our previous study [18] was limited to those without any basic residue to avoid complications that might arise due to such a residue. Even though the influence of a basic residue would be the most prominent for arginine, our current methodology can not handle the two channel problem that arises in the arginine case. Kinetic study of peptide ions with a histidine residue will be easier because mostly $b$ and $y$ type product ions are formed regardless of the energy regime. Results from the kinetic study on such peptide ions are presented in this paper.

\section{Experimental}

A schematic of the homebuilt MALDI-tandem time-offlight (TOF) mass spectrometer equipped with a PD cell assembly used in this work is shown in Figure 1. Its details were reported previously [21]. A brief description is as follows.

The instrument consists of a MALDI source with delayed extraction, a first stage TOF analyzer to timeseparate the prompt ions generated by MALDI, an ion gate and a second stage TOF analyzer equipped with a reflectron. $337 \mathrm{~nm}$ pulse from a nitrogen laser is used for MALDI with its fluence kept at two times the

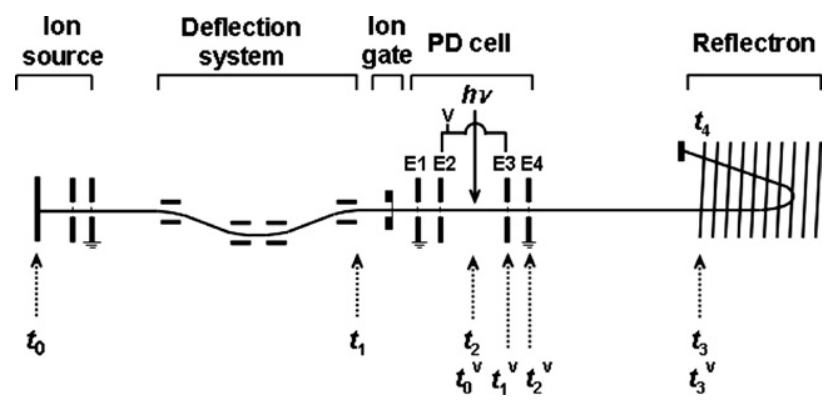

Figure 1. A schematic of the MALDI-PD tandem TOF equipped with a PD cell. Relevant time scales for PSD and voltage-on PD are marked. PSD occurs during $t_{1}-t_{3}$. In-cell and post-cell PDs occur during $t_{0}{ }^{\mathrm{V}}-t_{1} \mathrm{~V}$ and $t_{2}{ }^{\mathrm{V}}-t_{3} \mathrm{~V}$, respectively.

threshold value. A deflection system [23] installed inside the first stage TOF eliminates PSD product ions generated in this region. A cylindrically focused laser pulse at 266 or $193 \mathrm{~nm}$ passes through the first time focus in synchronization with the lowest $\mathrm{m} / \mathrm{z}$ isotopomer of a peptide ion. MCP detector output is treated as described previously [24] and averaged over 30,000 shots. Finally, the laser-off spectrum (PSD) is subtracted from the laser-on spectrum to obtain the laser-induced change or the PD spectrum.

The PD cell installed for time-resolved study consists of four grid electrodes (E1-E4). E1 and E4 are grounded while E2 and E3 are floated at the same potential. The center of the cell coincides with the PD laser irradiation spot. Each product ion peak $\left(\mathrm{m}_{2}{ }^{+}\right)$in a voltage-off PD spectrum splits into several components when high voltage is applied to the cell-the ones due to its formation from the precursor ion $\left(\mathrm{m}_{1}{ }^{+}\right)$inside (in-cell component, I) and outside (post-cell component, $\mathrm{P}$ ) the cell, and the consecutive components $\left(\mathrm{m}_{1}{ }^{+} \rightarrow \mathrm{m}_{\mathrm{i}}{ }^{+} \rightarrow\right.$ $\left.\mathrm{m}_{2}{ }^{+}, \mathrm{C}\right)$ with the first step occurring inside the cell and the second step outside. I and $\mathrm{C}$ are due to dissociation of $\mathrm{m}_{1}{ }^{+}$within around $0.1 \mu \mathrm{sec}$ after photoexcitation while $\mathrm{P}$ is due to dissociation occurring on the time scale of $0.2-5 \mu$ sec. The method to calibrate the detector gain for various types of ions was reported previously [18].

\section{Sample Preparation}

The peptide samples $\mathrm{HF}_{6}, \mathrm{~F}_{3} \mathrm{HF}_{3}$, and $\mathrm{F}_{6} \mathrm{H}$ with $90 \%$ purity were purchased from Peptron (Daejeon, Korea). The matrices, 2,5-dihydroxybenzoic acid (DHB), sinapinic acid (SA), and $\alpha$-cyano-4-hydroxycinnamic acid (CHCA), and other chemicals were purchased from Sigma (St. Louis, MO). A matrix solution was prepared daily using acetonitrile and $0.1 \%$ trifluoroacetic acid and was mixed with a peptide solution in dimethylsulfoxide. The final peptide concentrations prepared for PD experiments were $50 \mathrm{pmol} / \mu \mathrm{L}$. One $\mu \mathrm{L}$ of the solution was loaded on the sample plate. 


\section{Computational}

Details of the method to analyze PSD and PD data were explained previously [18]. A brief account is as follows.

$k(E)$ and the internal energy distribution $\left(P_{0}(E)\right)$ at specified values of $E_{0}, \Delta S^{\ddagger}$, and $T$ were calculated by the method reported previously $[19,20] . k_{\text {tot }}(E)$ and $P_{0}(E)$ calculated for $\left[\mathrm{HF}_{6}+\mathrm{H}\right]^{+}$with $E_{0}=0.55 \mathrm{eV}, \Delta S^{\ddagger}=$ $-35.2 \mathrm{eu}\left(1 \mathrm{eu}=4.184 \mathrm{~J} \mathrm{~K}^{-1} \mathrm{~mol}^{-1}\right)$, and $T=369 \mathrm{~K}$ are shown in Figure 2. Due to the dissociation of precursor ions, their internal energy distribution, $P_{t}(E)$, at any time $t$ after their formation becomes as follows.

$$
P_{t}(E)=P_{0}(E) \exp \left(-k_{\mathrm{tot}}(E) t\right)
$$

Arrival times of the precursor ion at some important locations are marked in Figure 1. Two different time zeroes are used, MALDI laser pulsing time for PSD $\left(t_{1}-t_{4}\right)$ and PD laser pulsing time for voltage-on PD $\left(t_{1}{ }^{\mathrm{V}}-t_{3}{ }^{\mathrm{V}}\right) . P_{t}(E)$ s at $t_{1}-t_{4}$ are marked as $P_{1}-P_{4}$ in Figure 2b. Shifting $P_{t}(E)$ at the center of the cell by the amount of photon energy, the energy distribution upon photoexcitation, $P_{0}{ }^{*}$, is obtained. The distributions at $t_{1}{ }^{\mathrm{V}}-t_{3} \mathrm{~V}$ calculated from $P_{0} \mathrm{~V}^{*}$ are marked as $P_{1}^{\mathrm{V}^{*}}-P_{3}{ }^{\mathrm{V}^{*}}$ in Figure 2b. The areas under $P_{\mathrm{i}}$ and $P_{\mathrm{i}}^{\mathrm{V}^{*}}$ are called $A_{\mathrm{i}}$ and $A_{\mathrm{i}}{ }^{\mathrm{V}^{*}}$, respectively. $P_{0}(E)$ is normalized $\left(A_{0}=1\right)$, while others are not.

From a PSD spectrum, we measure the $\Sigma$ [product ion]/[precursor ion] ratio (YPSD) and use the following

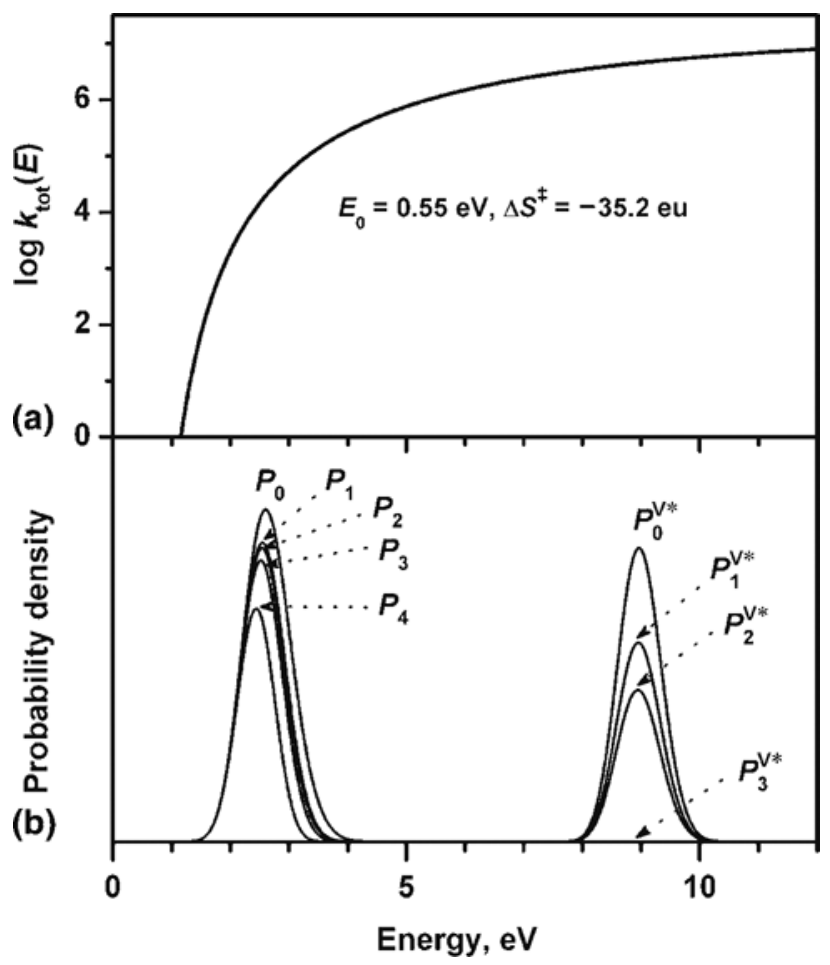

Figure 2. (a) $k_{\text {tot }}(E)$ and (b) $P_{0}(E)$ for $\left[\mathrm{HF}_{6}+\mathrm{H}\right]^{+}$calculated with $E_{0}=0.55 \mathrm{eV}, \Delta S^{\ddagger}=-35.2 \mathrm{eu}$, and $T=369 \mathrm{~K} . P_{\mathrm{i}}(E) \mathrm{s}$ are distributions at various locations marked in Figure 1. $P_{\mathrm{i}} \mathrm{V}^{*}(E)$ are distributions after absorption of one $193 \mathrm{~nm}$ photon, calculated for voltage $(3 \mathrm{kV})$-on PD at various locations. inequalities [18] to relate it with the areas calculated above.

$$
\left(A_{1}-A_{3}\right) / A_{3} \leq \mathrm{YPSD} \leq\left(A_{1}-A_{3}\right) / A_{4}
$$

From a voltage-on PD spectrum, we measure the total intensity of product ions formed outside $(\Sigma[\mathrm{P}])$ and inside $(\Sigma[I]+\Sigma[C])$ the cell and relate their ratio (CPD), $\Sigma[P] /(\Sigma[\mathrm{I}]+\Sigma[\mathrm{C}])$, with the calculated areas using the following inequalities [18].

$$
0.7 \mathrm{CPD} \leq\left(A_{2}^{\mathrm{V} *}-A_{3}^{\mathrm{V} *}\right) /\left(A_{0}^{\mathrm{V} *}-A_{1}^{\mathrm{V} *}\right) \leq 1.3 \mathrm{CPD}
$$

Actual analysis was done as follows. $k_{\text {tot }}(E)$ and $P_{0}(E)$ were calculated with more than ten million sets of $\left(E_{0}\right.$, $\left.\Delta S^{\ddagger}, T\right), E_{0}$ at $0.005 \mathrm{eV}$ interval, $\Delta S^{\ddagger}$ at $0.1 \mathrm{eu}$ interval, and $T$ at $10 \mathrm{~K}$ interval, from which $A_{\mathrm{i}}$ and $A_{\mathrm{i}} \mathrm{V}^{*}$ were evaluated. Then, the sets simultaneously satisfying eq 2 for YPSD data and eq 3 for 193 and $266 \mathrm{~nm}$ CPD data were selected. To further narrow the sets, those compatible with the data acquired for the precursor ions formed by different matrices were selected.

\section{Results}

Measurement of YPSD and CPD can be affected by MALDI laser fluence. Hence, it is needed to control the fluence for reproducible results. For each matrix used, we measured the threshold fluence for MALDI and used twice as much fluence in actual measurements. To assure one-photon absorption in PD, we adjusted the PD laser intensity to $5 \%$ photodepletion of a precursor ion signal. Then, PD spectral patterns did not change with the intensity. We estimate [14] that $1 \%$ of the total dissociation arises from multi-photon absorption under this condition.

\section{PSD}

PSD spectrum of $\left[\mathrm{HF}_{6}+\mathrm{H}\right]^{+}$-the first and second $\mathrm{H}$ indicate the histidine residue and the additional proton, respectively - generated by CHCA-MALDI is shown in Figure 3a. The spectrum was normalized to the precursor ion intensity. The spectra for the same ion generated by DHB- and SA-MALDI are not shown because the spectral patterns are similar regardless of the matrix used. The relative intensities of the product ions were in the order $\mathrm{DHB}<\mathrm{SA}<\mathrm{CHCA}$, in agreement with the general perception [25] that DHB, SA, and CHCA are "cold," "intermediate," and "hot" matrices, respectively, in peptide MALDI. $\mathrm{b}_{n}(n=2-6)$ Ions were the major product ions. In addition, $\mathrm{a}_{n}(n=2,4-6), \mathrm{y}_{n}(n=$ $2,3,5)$, and the internal ions $\mathrm{F}_{n}(n=2-4)$ appeared weakly. Important is the fact that all of these product ions can be formed via a set of similar channels, viz. oxazolone pathways, the requirement for the one-channel treatment. Dominance of $\mathrm{b}_{n}$ can also be explained based on the oxazolone mechanism-presence of a basic histidine residue at the $\mathrm{N}$-terminus favors $\mathrm{b}_{n}$ 


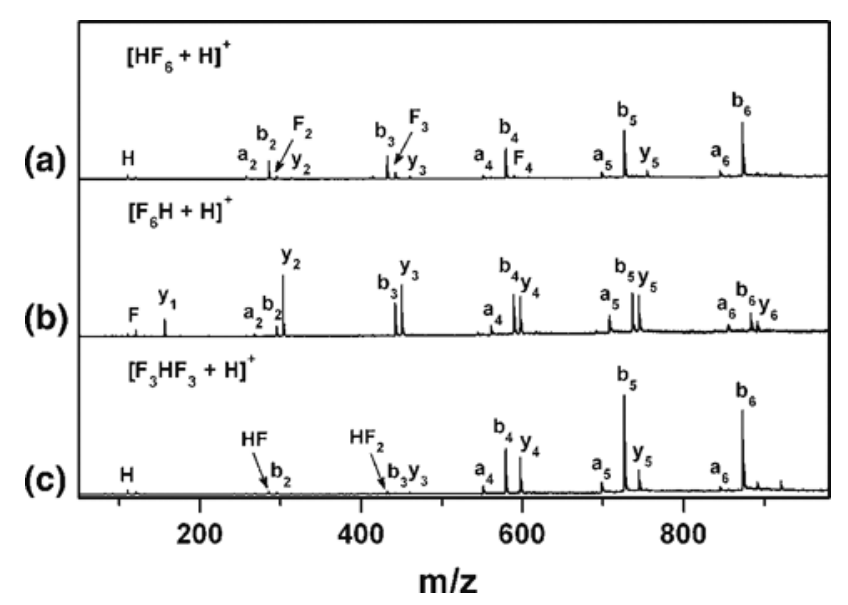

Figure 3. PSD spectra of (a) $\left[\mathrm{HF}_{6}+\mathrm{H}\right]^{+}$, (b) $\left[\mathrm{F}_{6} \mathrm{H}+\mathrm{H}^{+}\right.$, and (c) $\left[\mathrm{F}_{3} \mathrm{HF}_{3}+\mathrm{H}\right]^{+}$generated by CHCA-MALDI. Product ion peak heights are normalized to that of the precursor ion in each spectrum. For DHB- and SA-MALDI, spectral patterns are similar, while relative intensities are in the order $\mathrm{DHB}<\mathrm{SA}<\mathrm{CHCA}$.

(proton retention by oxazolone derivatives) rather than $\mathrm{y}_{n}$ (proton retention by smaller peptides). In Table 1 , YPSD values for $\left[\mathrm{HF}_{6}+\mathrm{H}\right]^{+}$generated with $\mathrm{DHB}, \mathrm{SA}$, and CHCA as matrices are compared with those for $\left[\mathrm{Y}_{6}+\mathrm{H}\right]^{+}$and $\left[\mathrm{F}_{5}+\mathrm{H}\right]^{+}$reported previously [18]. For each matrix used, the PSD yield for $\left[\mathrm{HF}_{6}+\mathrm{H}^{+}\right.$is smaller than those for $\left[\mathrm{Y}_{6}+\mathrm{H}\right]^{+}$and $\left[\mathrm{F}_{5}+\mathrm{H}\right]^{+}$by a factor of 2 to 5 , viz. dissociation gets less efficient as a histidine residue is present. Even though experimental data acquired using the above three matrices were used for kinetic analysis in the previous work, results from SA data always lay between DHB and CHCA results, and did not help to narrow down $E_{0}$ and $\Delta S^{\ddagger}$ values. In this work, we present only DHB and CHCA data and their analysis.

PSD spectra of $\left[\mathrm{F}_{6} \mathrm{H}+\mathrm{H}\right]^{+}$and $\left[\mathrm{F}_{3} \mathrm{HF}_{3}+\mathrm{H}\right]^{+}$ formed by CHCA-MALDI are also shown in Figure 3. $\mathrm{b}_{n}(n=2-6), \mathrm{a}_{n}(n=2,4-6)$, and $\mathrm{y}_{n}(n=1-6)$ are major product ions in PSD of $\left[\mathrm{F}_{6} \mathrm{H}+\mathrm{H}\right]^{+}$. For the $\mathrm{y}_{n} / \mathrm{b}_{n}$ pairs formed by cleavage of each amide bond, dominance of $\mathrm{y}_{n}$ containing the basic histidine residue is not as overwhelming as for $\mathrm{b}_{n}$ in PSD of $\left[\mathrm{HF}_{6}+\mathrm{H}\right]^{+}$. For example, $\mathrm{y}_{1}, \mathrm{y}_{2}, \mathrm{y}_{3}$, and $\mathrm{y}_{4}$ are comparable to $\mathrm{b}_{6}, \mathrm{~b}_{5}, \mathrm{~b}_{4}$, and $b_{3}$, respectively. That is, the histidine residue at the C-terminus is not as influential as the same residue at the N-terminus in determining which moiety in a proton-bound dimer would retain the additional proton. $\mathrm{b}_{n}(n=2-6), \mathrm{a}_{n}(n=4-6)$, and $\mathrm{y}_{n}(n=3-5)$ are major product ions in PSD (Figure c) of $\left[\mathrm{F}_{3} \mathrm{HF}_{3}+\mathrm{H}\right]^{+}$also. Among $\mathrm{b}_{n}$ ions, $\mathrm{b}_{4}, \mathrm{~b}_{5}$, and $\mathrm{b}_{6}$ containing the histidine residue are particularly intense, while $b_{2}$ and $b_{3}$ are weak, in agreement with the $b / y$ branching model described above. YPSD values for $\left[\mathrm{F}_{6} \mathrm{H}+\mathrm{H}\right]^{+}$and $\left[\mathrm{F}_{3} \mathrm{HF}_{3}+\mathrm{H}\right]^{+}$generated by DHB- and CHCA-MALDI are listed in Table 1. For each matrix used, YPSD values for the three precursor ions $\left[\mathrm{HF}_{6}+\mathrm{H}\right]^{+},\left[\mathrm{F}_{6} \mathrm{H}+\mathrm{H}\right]^{+}$, and $\left[\mathrm{F}_{3} \mathrm{HF}_{3}+\mathrm{H}\right]^{+}$are quite similar, suggesting that the influence of the histidine residue on dissociation efficiency is similar regardless of its position inside a peptide ion.

\section{$P D$}

Voltage-off $193 \mathrm{~nm}$ PD spectra of $\left[\mathrm{HF}_{6}+\mathrm{H}^{+},\left[\mathrm{F}_{6} \mathrm{H}+\right.\right.$ $\mathrm{H}]^{+}$, and $\left[\mathrm{F}_{3} \mathrm{HF}_{3}+\mathrm{H}\right]^{+}$formed by DHB-MALDI are shown in Figure 4. PD spectra obtained at $266 \mathrm{~nm}$ or those obtained with CHCA-MALDI are similar to those in Figure 4 and hence are not shown. Major product ions appearing in PD spectra are essentially the same as those in PSD spectra, such as $\mathrm{b}_{n}(n=2-5), \mathrm{a}_{n}(n=2-5)$, $\mathrm{y}_{n}(n=2,3)$, and $\mathrm{F}_{n}(n=1-3)$ from $\left[\mathrm{HF}_{6}+\mathrm{H}\right]^{+}$. The main difference between PSD and PD spectra is that large product ions are either absent or weaker in the latter spectra. This does not necessarily mean that these ions are not formed at all or are formed weakly by PD. Rather, large product ions formed by PD may have further dissociated to smaller product ions, as found in our previous time-resolved, viz. voltage-on, PD studies $[17,21]$.

One hundred ninety-three nm PD spectrum of $\left[\mathrm{HF}_{6}+\right.$ $\mathrm{H}]^{+}$recorded with $3 \mathrm{kV}$ applied to the cell is shown in Figure 5. As mentioned previously, each product ion peak in a voltage-off PD spectrum splits into post-cell $(\mathrm{P})$, in-cell (I), and consecutive (C) components when high voltage is applied to the cell. We also mentioned that not only the dissociations resulting in I but also the first-step dissociations for $\mathrm{C}$ occur inside the cell, while those resulting in $\mathrm{P}$ occur outside. $\mathrm{P}$ components can be easily identified [21], as marked in the expanded spectra shown in the figure. An instrument-based method to identify $\mathrm{I}$ and the intermediate ion $\left(\mathrm{m}_{\mathrm{i}}^{+}\right)$contributing to each $C$ has been developed recently [26]. CPDs at 266 and $193 \mathrm{~nm}$ measured for $\left[\mathrm{HF}_{6}+\mathrm{H}\right]^{+},\left[\mathrm{F}_{6} \mathrm{H}+\mathrm{H}\right]^{+}$, and $\left[\mathrm{F}_{3} \mathrm{HF}_{3}+\mathrm{H}\right]^{+}$formed by MALDI with different matrices are listed in Table 1. First to note from the data is that CPDs for the three ions are quite similar when the matrix and the photon wavelength are the same. For example, CPDs at $193 \mathrm{~nm}$ for $\left[\mathrm{HF}_{6}+\mathrm{H}^{+},\left[\mathrm{F}_{6} \mathrm{H}+\mathrm{H}\right]^{+}\right.$, and $\left[\mathrm{F}_{3} \mathrm{HF}_{3}+\mathrm{H}\right]^{+}$formed by CHCA-MALDI are 1.59,

Table 1. Experimental YPSD and CPD data for some peptide ions with and without a histidine residue generated by MALDI with $\mathrm{DHB}, \mathrm{SA}$, and CHCA as matrices ${ }^{\mathrm{a}}$

\begin{tabular}{lllll}
\hline & & & \multicolumn{2}{c}{ CPD } \\
\cline { 3 - 5 } Peptide ions & Matrices & YPSD & $193 \mathrm{~nm}$ & $266 \mathrm{~nm}$ \\
\hline \hline$\left[\mathrm{HF}_{6}+\mathrm{H}\right]^{+}$ & DHB & 0.052 & 1.98 & 3.20 \\
& SA & 0.104 & 1.64 & 2.92 \\
& CHCA & 0.129 & 1.59 & 2.63 \\
{$\left[\mathrm{~F}_{6} \mathrm{H}+\mathrm{H}\right]^{+}$} & DHB & 0.038 & 2.22 & 3.08 \\
& CHCA & 0.153 & 1.65 & 2.81 \\
{$\left[\mathrm{~F}_{3} \mathrm{HF}_{3}+\mathrm{H}\right]^{+}$} & DHB & 0.039 & 1.89 & 3.20 \\
& CHCA & 0.141 & 1.62 & 2.68 \\
{$\left[\mathrm{Y}_{6}+\mathrm{H}\right]^{+}$} & DHB & 0.160 & 0.717 & 1.67 \\
& SA & 0.459 & 0.508 & 0.938 \\
{$\left[\mathrm{~F}_{5}+\mathrm{H}\right]^{+}$} & CHCA & 0.722 & 0.282 & 0.829 \\
& DHB & 0.114 & 0.414 & 0.999 \\
& SA & 0.298 & 0.219 & 0.642 \\
& CHCA & 0.497 & 0.156 & 0.390 \\
\hline
\end{tabular}

${ }^{a}$ Data for $\left[\mathrm{Y}_{6}+\mathrm{H}\right]^{+}$and $\left[\mathrm{F}_{5}+\mathrm{H}\right]^{+}$are taken from reference [18]. 


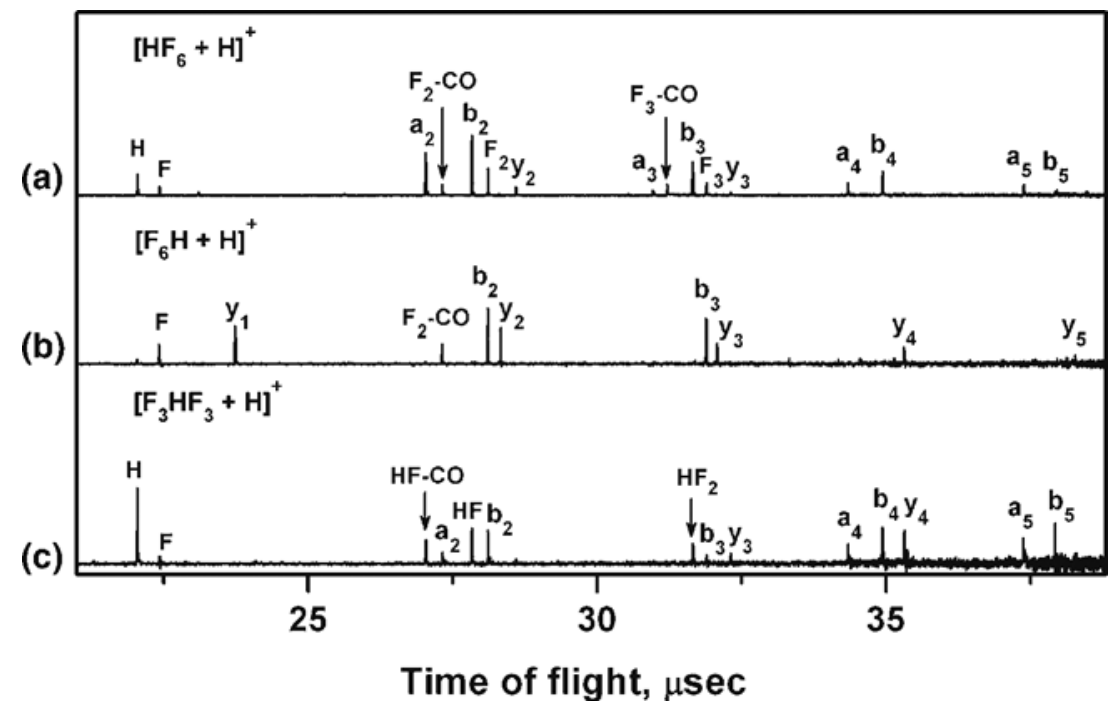

Figure 4. Voltage-off $193 \mathrm{~nm}$ PD spectra of $(\mathbf{a})\left[\mathrm{HF}_{6}+\mathrm{H}\right]^{+}$, (b) $\left[\mathrm{F}_{6} \mathrm{H}+\mathrm{H}\right]^{+}$, and $(\mathbf{c})\left[\mathrm{F}_{3} \mathrm{HF}_{3}+\mathrm{H}\right]^{+}$ formed by DHB-MALDI.

1.65, and 1.62, respectively. This suggests that the influence of the histidine residue on dissociation kinetics is similar regardless of its position inside a peptide ion, as also concluded from similar YPSD values. Secondly, CPDs for the above peptide ions are noticeably larger, or dissociations occur more slowly, than those for $\left[\mathrm{Y}_{6}+\mathrm{H}\right]^{+}$and $\left[\mathrm{F}_{5}+\mathrm{H}\right]^{+}$. Such a difference can be seen more clearly in the voltage-on PD pattern for each product ion, viz. dominance of $\mathrm{P}$ in $\mathrm{PD}$ of $\left[\mathrm{HF}_{6}+\mathrm{H}\right]^{+}$ versus dominance of $\mathrm{I}+\mathrm{C}$ in $\mathrm{PD}$ of $\left[\mathrm{Y}_{6}+\mathrm{H}\right]^{+}[18]$ as demonstrated in Figure 6. The third trend is that CPD decreases as the photon energy increases from $4.66 \mathrm{eV}$ $(266 \mathrm{~nm})$ to $6.42 \mathrm{eV}(193 \mathrm{~nm})$, in qualitative agreement with RRKM. Smaller CPD with CHCA (hot matrix) than with DHB (cold matrix) is also compatible with RRKM.
Finally, relative changes in CPD as the photon energy changes from 4.66 to $6.42 \mathrm{eV}$ are smaller for peptide ions with a histidine residue than for those without.

Since the fractions of the post-cell and in-cell dissociations are roughly proportional to $\left[\exp \left(-k_{\text {tot }} t_{2} \mathrm{~V}\right)-\right.$ $\left.\exp \left(-k_{\mathrm{tot}} t_{3}^{\mathrm{V}}\right)\right]$ and $\left[1-\exp \left(-k_{\mathrm{tot}} t_{1}^{\mathrm{V}}\right)\right]$, respectively, the average PD rate constant $\left(k_{\mathrm{tot}}\right)$ can be estimated by equating their ratio with $\mathrm{CPD}$. For $\left[\mathrm{HF}_{6}+\mathrm{H}\right]^{+}$formed by DHB-MALDI, $k_{\text {tot }}$ thus estimated is $2.5 \times 10^{6}$ and $3.6 \times$ $10^{6} \mathrm{~s}^{-1}$ for 266 and $193 \mathrm{~nm}$ PD, respectively. Corresponding values for $\left[\mathrm{Y}_{6}+\mathrm{H}\right]^{+}$formed by DHB-MALDI are $4.1 \times 10^{6}$ and $7.0 \times 10^{6} \mathrm{~s}^{-1}$. For both peptide ions, 1.76 $\mathrm{eV}$ increase in photon energy increases $k_{\text {tot }}$ only a little, by a factor of 1.4 for $\left[\mathrm{HF}_{6}+\mathrm{H}\right]^{+}$and by a factor of 1.7 for $\left[\mathrm{Y}_{6}+\mathrm{H}\right]^{+}$. According to RRKM, the weak depen-

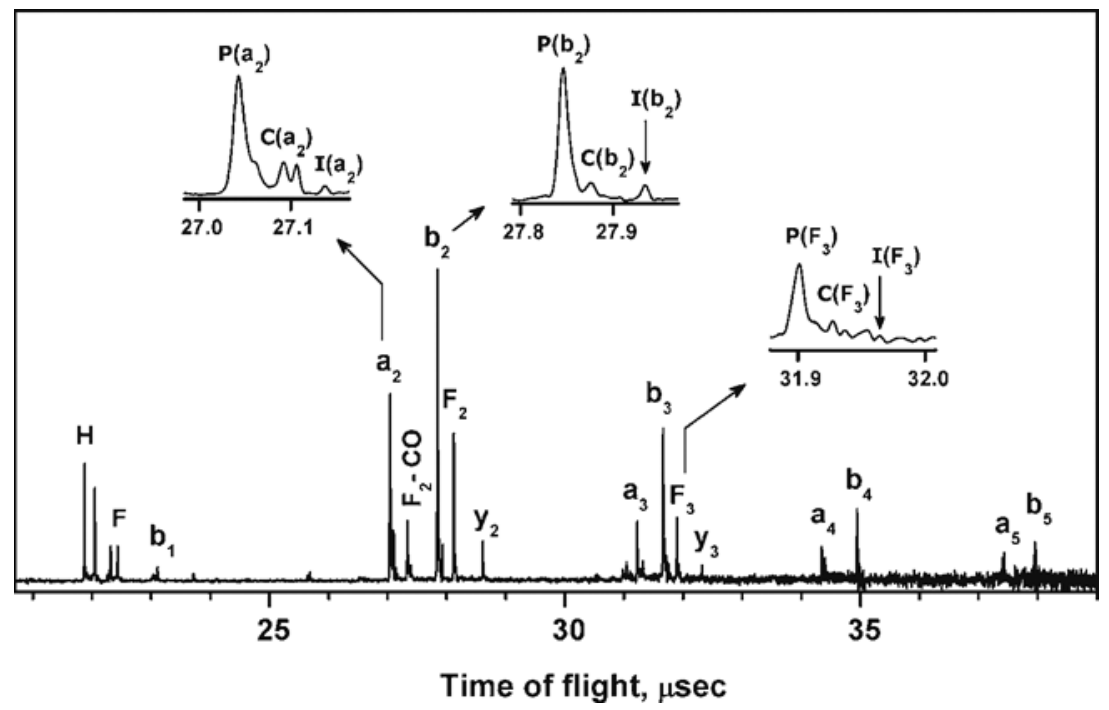

Figure 5. One hundred ninety-three nm PD spectrum of $\left[\mathrm{HF}_{6}+\mathrm{H}\right]^{+}$formed by CHCA-MALDI recorded with $3 \mathrm{kV}$ applied to the cell. I and $\mathrm{C}$ are due to dissociation of $\left[\mathrm{HF}_{6}+\mathrm{H}\right]^{+}$inside the cell within $93 \mathrm{~ns}$ after photoexcitation, while P components are formed outside the cell during $0.16-5.0 \mu \mathrm{s}$. 
(a)

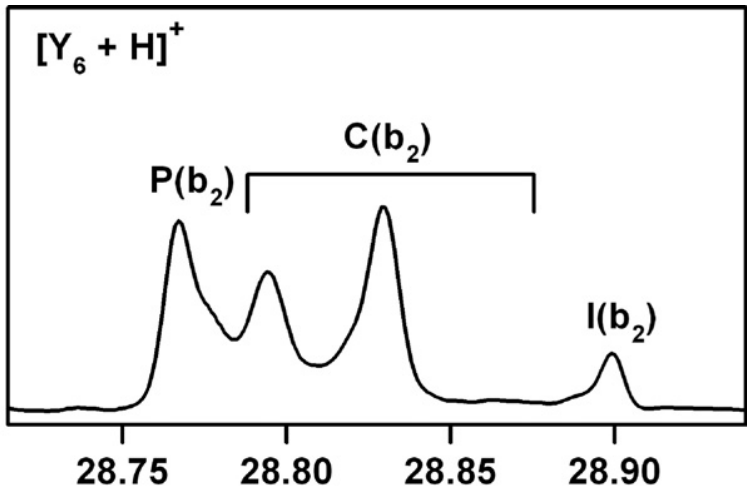

(b)

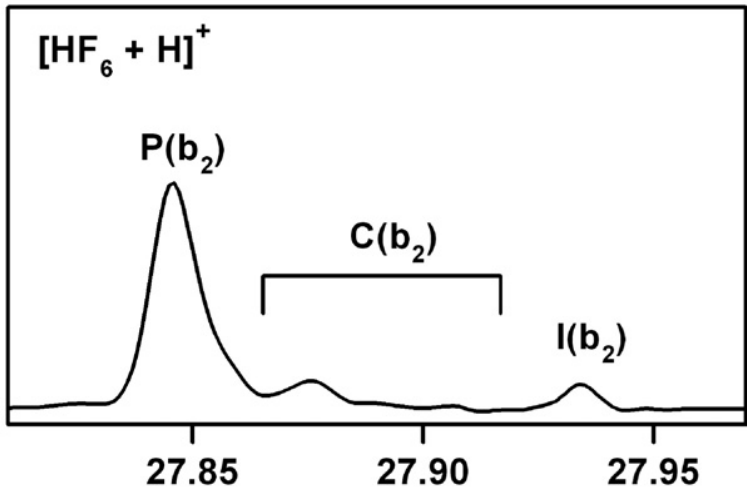

Time of flight, $\mu \mathrm{sec}$

Figure 6. Splitting of $b_{2}$ product ion peak due to the cell voltage $(3 \mathrm{kV})$ in $193 \mathrm{~nm} \mathrm{PD}$ of (a) $\left[\mathrm{Y}_{6}+\mathrm{H}\right]^{+}$and (b) $\left[\mathrm{HF}_{6}+\mathrm{H}\right]^{+}$formed by CHCA-MALDI. In-cell, post-cell, and consecutive components are marked as I, $\mathrm{P}$, and $\mathrm{C}$, respectively. $\mathrm{I}+\mathrm{C}$ is larger than $\mathrm{P}$ in (a), while smaller than $\mathrm{P}$ in (b).

dence of $k_{\mathrm{tot}}$ on $E$ means that PD of peptide ions occur via tight transition states with small $\Delta S^{\ddagger}$ and that the presence of a histidine residue further lowers $\Delta S^{\ddagger}$.

\section{Kinetic Analysis}

There is a possibility that less efficient dissociation in the presence of a histidine residue, which will be called the histidine effect, may just reflect the difference in vibrational frequencies and mass between the ions investigated. To check this, we calculated $k_{\text {tot }}(E)$ functions for $\left[\mathrm{HF}_{6}+\mathrm{H}\right]^{+}$and $\left[\mathrm{Y}_{6}+\mathrm{H}\right]^{+}$, using the same kinetic parameters and found that they were essentially the same, i.e., the effect is genuine.

Kinetic analysis was carried out as described in the computational section. It is to be mentioned that there was an error in the software used in the previous work. Hence, the data for $\left[\mathrm{Y}_{6}+\mathrm{H}\right]^{+}$and $\left[\mathrm{F}_{5}+\mathrm{H}\right]^{+}$have been retreated in this work, even though the final results were rather similar to those reported previously [18]. $E_{0}$ and $\Delta S^{\ddagger}$ thus determined for $\left[\mathrm{HF}_{6}+\mathrm{H}\right]^{+}$are $0.55 \pm 0.07$ $\mathrm{eV}$ and $-35.2 \pm 6.2 \mathrm{eu}$, respectively, which, in turn, determine $k_{\text {tot }}(E)$ as shown in Figure 2. The effective internal temperatures are $345 \pm 41,363 \pm 42$, and $369 \pm$ $44 \mathrm{~K}$ for MALDI with DHB, SA, and CHCA, respectively. For $\left[\mathrm{F}_{6} \mathrm{H}+\mathrm{H}\right]^{+}$and $\left[\mathrm{F}_{3} \mathrm{HF}_{3}+\mathrm{H}\right]^{+}$, we measured data only with DHB- and CHCA-MALDI. The results are listed in Table 2. Even though the positions of the histidine residue are different in $\left[\mathrm{HF}_{6}+\mathrm{H}\right]^{+},\left[\mathrm{F}_{6} \mathrm{H}+\right.$ $\mathrm{H}]^{+}$, and $\left[\mathrm{F}_{3} \mathrm{HF}_{3}+\mathrm{H}\right]^{+}, E_{0}$ and $\Delta S^{\ddagger}$ are essentially the same. The parameters for two peptide ions, $\left[\mathrm{Y}_{6}+\mathrm{H}\right]^{+}$ and $\left[\mathrm{F}_{5}+\mathrm{H}\right]^{+}$, are also listed in Table 2. For $\left[\mathrm{F}_{5}+\mathrm{H}\right]^{+}$, $\left(E_{0}, \Delta S^{\ddagger}\right)$ sets from DHB-MALDI results are listed because DHB- and CHCA-MALDI results did not overlap, even though very close, and because DHB-MALDI results were close to the final results for other ions. This suggests that the systematic errors involved in this work might be larger than estimated. It is to be mentioned that $E_{0}, \Delta S^{\ddagger}$, and $T$, for two groups of peptide ions, viz. those with and without a histidine residue, are similar, especially when large errors quoted in the table are taken into account-errors were estimated at the $95 \%$ confidence limit. However, the data in Table 2, taken together, show that $E_{0}, \Delta S^{\ddagger}$, and $T$ decrease in the presence of a histidine residue.

\section{Discussion}

According to quantum chemical calculations $[8,27], E_{0}$ and $\Delta S^{\ddagger}$ for the dissociation of $\left[\mathrm{G}_{3}+\mathrm{H}\right]^{+}$to $\mathrm{b}_{2}$ were 1.14 $\mathrm{eV}$ and $-0.86 \mathrm{eu}$, respectively. Both of these are much larger than those ( $E_{0}$ around $0.54 \mathrm{eV}$ and $\Delta S^{\ddagger}$ around $-36 \mathrm{eu})$ determined here. As long as we adhered to the assumptions adopted in this work, we could not fit PSD and PD yield data with $E_{0}$ and $\Delta S^{\ddagger}$ values close to the theoretical ones. It is difficult to pinpoint the exact cause for the discrepancy between the theoretical and experimental $E_{0}$ and $\Delta S^{\ddagger}$ values. Even though the validity of

Table 2. Internal temperature $(T$, in $K)$ of some peptide ions with and without a histidine residue generated by MALDI with DHB, $\mathrm{SA}$, and CHCA as matrices and $E_{0}$ (in eV) and $\Delta S^{\ddagger}$ (in eu) for their dissociation ${ }^{\mathrm{a}}$

\begin{tabular}{|c|c|c|c|c|c|}
\hline & \multirow[b]{2}{*}{$E_{0}$} & \multirow[b]{2}{*}{$\Delta S^{\ddagger}$} & \multicolumn{3}{|c|}{ Internal temperature } \\
\hline & & & DHB & SA & $\mathrm{CHCA}$ \\
\hline$\left[\mathrm{HF}_{6}+\mathrm{H}\right]^{+}$ & $0.55 \pm 0.07$ & $-35.2 \pm 6.2$ & $345 \pm 41$ & $363 \pm 42$ & $369 \pm 44$ \\
\hline$\left[\mathrm{F}_{6} \mathrm{H}+\mathrm{H}\right]^{+}$ & $0.53 \pm 0.05$ & $-36.8 \pm 4.4$ & $329 \pm 27$ & - & $364 \pm 29$ \\
\hline$\left[\mathrm{F}_{3} \mathrm{HF}_{3}+\mathrm{H}\right]^{+}$ & $0.54 \pm 0.06$ & $-36.0 \pm 5.3$ & $331 \pm 33$ & - & $363 \pm 34$ \\
\hline$\left[\mathrm{Y}_{6}+\mathrm{H}\right]^{+}$ & $0.60 \pm 0.03$ & $-28.4 \pm 2.1$ & $396 \pm 22$ & $445 \pm 29$ & $469 \pm 22$ \\
\hline$\left[\mathrm{F}_{5}+\mathrm{H}\right]^{+}$ & $0.57 \pm 0.10$ & $-30.2 \pm 6.3$ & $383 \pm 62$ & - & - \\
\hline
\end{tabular}

aResults for $\left[\mathrm{Y}_{6}+\mathrm{H}\right]^{+}$and $\left[\mathrm{F}_{5}+\mathrm{H}\right]^{+}$have been obtained by retreatment. 
RRKM adopted in this work cannot be tested rigorously, the overall patterns of the spectral data acquired seem to be compatible with this. We also assumed internal thermal equilibrium for ions generated by MALDI, another aspect that has not been confirmed experimentally. Inherent inaccuracy of quantum chemical calculations, especially for the transition structures in the reactions of very large molecules, can be another cause for the discrepancy.

In the previous study, we proposed that much smaller $E_{0}$ and $\Delta S^{\ddagger}$ values than theoretical ones might be an indication for intramolecular interactions in the transition structures. Further lowering of $\Delta S^{\ddagger}$ in the presence of a histidine residue observed in this work is another indication for such interactions. In particular, the basic nature of histidine suggests that the interactions may involve the additional proton. That is, one of the nitrogen atoms in this residue, or the nitrogen atom at the N-terminus in the absence of this residue, may coordinate to the additional proton attached to the five-membered ring, resulting in a macrocyclic transition structure with low entropy. This is in contrast with the original oxazolone pathway in which the additional proton initially attached to the nitrogen atom at the N-terminus is thought to completely migrate to an amide nitrogen. Both the original oxazolone pathway and the present modified version may exist for large peptide ions. Based on highly negative $\Delta S^{\ddagger}$ found in the kinetic studies, we propose that the latter path is the minimum energy path (MEP).

According to the laser-induced desorption study of molecular ions embedded in a matrix by Vertes et al. [28], the matrix plume temperature is in the order DHB > $\mathrm{SA}>\mathrm{CHCA}$. However, there have been many claims $[22,25]$ that the internal temperature order for peptide ions formed by MALDI is the opposite. Results from our kinetic studies are in the order DHB $<\mathrm{SA}<\mathrm{CHCA}$ for peptide ions with and without a histidine residue.

Two mechanisms are frequently mentioned for ion formation [22] in MALDI, ion formations in the condensed phase (preformed ion model) and in the gas phase via proton transfer (gas-phase proton transfer model). In the more popular gas-phase proton transfer model, $T$ of a peptide ion would be affected not only by the plume temperature but also by $\Delta H$ in proton transfer reactions. Then, use of a matrix with larger proton affinity (PA) might result in lower $T$. However, the $\mathrm{DHB}<\mathrm{SA}<\mathrm{CHCA}$ order found in the experiments is in disagreement with a recent compilation of matrix PA data [22]. Experimental data also show that for each matrix used, peptide ions with a histidine residue have lower internal temperature than those without. This is unexpected because the presence of a basic histidine residue would lower $\Delta H$ in proton transfer and hence increase $T$. A simple-minded speculation based on the preformed ion model suggests that $T$ of a peptide ion is the same as the plume temperature and hence is unaffected by the presence of a histidine residue, again in disagreement with the experimental results. At the moment, we do not have any explanation for the internal temperature order observed in this work.

\section{Conclusion}

Internal temperature $(T)$ of peptide ions with a histidine residue and their dissociation kinetic parameters $\left(E_{0}\right.$ and $\Delta S^{\ddagger}$ ) have been determined by using the kinetic method developed previously. $E_{0}, \Delta S^{\ddagger}$, and $T$ have been found to be a little lower than those for peptide ions without any basic residue. In both cases, $\Delta S^{\ddagger}$ was much lower than found in quantum chemical reaction path search for small model systems. For large peptide ions, we propose that a basic nitrogen atom, either at the histidine residue or at the N-terminus, coordinates to the additional proton attached to the reaction center in the transition structure. This is in contrast with the conventional view known as the mobile proton model that postulates complete detachment of the additional proton from the above basic sites.

Against our expectation based on popular models for ion formation in MALDI, presence of a histidine residue was found to lower $T$ of peptide ions. More accurate measurements of proton affinities of peptides and matrices, and matrix plume temperatures, are needed to better understand ion formation processes in MALDI.

\section{Acknowledgments}

The authors acknowledge financially support for this work by the Korea Research Foundation, Republic of Korea, and by the Biosignal Analysis Technology Innovation Program (M1064501000206N4501-00,210) of the Ministry of Education, Science and Technology, Republic of Korea. SHY thanks the Ministry of Education, Science and Technology, Republic of Korea, for Brain Korea 21 Fellowship.

\section{References}

1. Kinter, M.; Sherman, N. E. Protein Sequencing and Identification Using Tandem Mass Spectrometry. John Wiley: New York, 2000; pp 64-116, pp $238-268$.

2. Martin, S. A.; Biemann, K. Sequencing of Peptides by Tandem Mass Spectrometry and High-Energy Collision-Induced Dissociation. In Methods in Enzymology, vol. CXCIII. Mass Spectrometry; McCloskey, J. A., Ed.; Academic Press: New York, 1990; pp 455-479.

3. Wysocki, V. H.; Tsaprailis, G.; Smith, L. L.; Breci, A. Mobile and Localized Protons: A Framework for Understanding Peptide Dissociation. J. Mass Spectrom. 2000, 35, 1399-1406.

4. Polce, M. J.; Ren, D.; Wesdemiotis, C. Dissociation of the Peptide Bond in Protonated Peptides. J. Mass Spectrom. 2000, 35, 1391-1398.

5. Medzihradszky, K. F. Peptide Sequence Analysis. In Methods in Enzymology, vol. CDII. Biological Mass Spectrometry; Burlingame, A. L., Ed.; Academic Press: San Diego, 2005; pp 209-244.

6. Hillenkamp, F.; Karas, M.; Beavis, R. C.; Chait, B. T. Matrix-Assisted Laser Desorption/Ionization Mass Spectrometry of Biopolymers. Anal. Chem. 1991, 63, 1193A-1203A.

7. Electrospray Ionization Mass Spectrometry, Cole, R. B., Ed.; WileyInterscience: New York, 1997; pp 3-64.

8. Paizs, B.; Suhai, S. Combined Quantum Chemical and RRKM Modeling of the Main Fragmentation Pathways of Protonated GGG. II. Formation of $\mathrm{b}_{2}, \mathrm{y}_{1}$, and $\mathrm{y}_{2}$ ions. Rapid Commun. Mass Spectrom. 2002, 16, 375-389.

9. Paizs, B.; Suhai, S. Fragmentation Pathways of Protonated Peptides. Mass Spectrom. Rev. 2005, 24, 508-548.

10. El Aribi, H.; Rodriquez, C. F.; Almeida, D. R. P.; Ling, Y.; Mak, W. W. N.; Hopkinson, A. C.; Siu, K. W. M. Elucidation of Fragmentation Mechanisms of Protonated Peptide Ions and Their Products: A Case Study on Glycylglycylglycine Using Density Functional Theory and Threshold Collision-Induced Dissociation. J. Am. Chem. Soc. 2003, 125, 9229-9236.

11. Laskin, J.; Bailey, T. H.; Furtrell, J. H. Mechanisms of Peptide Fragmentation from Time- and Energy-Resolved Surface-Induced Dissociation 
Studies: Dissociation of Angiotensin Analogs. Int. J. Mass Spectrom. 2006, 249-250, 462-472.

12. Cui, W.; Thompson, M. S.; Reilly, J. P. Pathways of Peptide Ion Fragmentation Induced by Vacuum Ultraviolet Light. J. Am. Soc. Mass Spectrom. 2005, 16, 1384-1398.

13. Choi, K. M.; Yoon, S. H.; Sun, M.; Oh, J. Y.; Moon, J. H.; Kim, M. S. Characteristics of Photodissociation at $193 \mathrm{~nm}$ of Singly Protonated Peptides Generated by Matrix-Assisted Laser Desorption Ionization (MALDI). J. Am. Soc. Mass Spectrom. 2006, 17, 1643-1653.

14. Oh, J. Y.; Moon, J. H.; Kim, M. S. Tandem Time-of-Flight Mass Spectrometer for Photodissociation of Biopolymer Ions Generated by Matrix-Assisted Laser Desorption Ionization (MALDI-TOF-PD-TOF) Using a Linear-Plus-Quadratic Potential Reflectron. J. Am. Soc. Mass Spectrom. 2004, 15, 1248-1259.

15. Holbrook, K. A.; Pilling, M. J.; Robinson, S. H. Unimolecular Reactions; Wiley: Chichester, 1996; pp 39-78.

16. Schlag, E. W.; Levine, R. D. On the Unimolecular Dissociation of Large Molecules. Chem. Phys. Lett. 1989, 163, 523-530.

17. Yoon, S. H.; Chung, Y. J.; Kim, M. S. Time-Resolved Photodissociation of Singly Protonated Peptides with an Arginine at the N-Terminus: A Statistical Interpretation. J. Am. Soc. Mass Spectrom. 2008, 19, 645-655.

18. Moon, J. H.; Yoon, S. H.; Kim, M. S. Temperature of Peptide Ions Generated by Matrix-Assisted Laser Desorption Ionization and Their Dissociation Kinetic Parameters. J. Phys. Chem. B 2009, 113, 2071-2076.

19. Moon, J. H.; Oh, J. Y.; Kim, M. S. A Systematic and Efficient Method to Estimate the Vibrational Frequencies of Linear Peptide and Protein Ions with Any Amino Acid Sequence for the Calculation of RiceRamsperger-Kassel-Marcus Rate Constant. J. Am. Soc. Mass Spectrom. 2006, 17, 1749-1757.
20. Moon, J. H.; Sun, M.; Kim, M. S. Efficient and Reliable Calculation of Rice-Ramsperger-Kassel-Marcus Unimolecular Reaction Rate Constants for Biopolymers: Modification of Beyer-Swinehart Algorithm for Degenerate Vibrations. J. Am. Soc. Mass Spectrom. 2007, 18, 1063-1069.

21. Yoon, S. H.; Kim, M. S. Development of a Time-Resolved Method for Photodissociation Mechanistic Study of Protonated Peptides: Use of a Voltage-Floated Cell in a Tandem Time-of-Flight Mass Spectrometer. J. Am. Soc. Mass Spectrom. 2007, 18, 1729-1739.

22. Knochenmuss, R. Ion Formation Mechanisms in UV-MALDI. Analyst 2006, 131, 966-986.

23. Yoon, S. H.; Moon, J. H.; Choi, K. M.; Kim, M. S. A Deflection System to Reduce the Interference from Post-Source Decay Product Ions in Photodissociation Tandem Time-of-Flight Mass Spectrometry. Rapid Commun. Mass Spectrom. 2006, 20, 2201-2208

24. Moon, J. H.; Yoon, S. H.; Kim, M. S. Construction of an Improved Tandem Time-of-Flight Mass Spectrometer for Photodissociation of Ions Generated by Matrix-Assisted Laser Desorption Ionization (MALDI). Bull. Korean Chem. Soc. 2005, 26, 763-768.

25. Gabelica, V.; Schulz, E.; Karas, M. Internal Energy Build-Up in MatrixAssisted Laser Desorption/Ionization. J. Mass Spectrom. 2004, 39, 579 593.

26. Shin, Y. S.; Moon, J. H.; Kim, M. S. Construction and Performance Test of a Multiplexed Multistage $\left(\mathrm{MS}^{n}\right)$ Time-of-Flight Mass Spectrometer. Anal. Chem. 2008, 80, 9700-9704.

27. Calculated at the geometries of the global minimum and the transition structure reported in reference 8

28. Luo, G.; Marginean, I.; Vertes, A. Internal Energy of Ions Generated by Matrix-Assisted Laser Desorption/Ionization. Anal. Chem. 2002, 74, 6185-6190. 